Manche sind 1 Zoll lang und frei ausgebildet, andere zu hackenförmig gebogenen Massen zusammengehäuft und verläuft dann, wenn die Individuen dünn werden, ein solches Aggregat ins Stängliche oder Fasrige. Die Krystalle sind vollkommen hexaëdrisch spaltbar und verhalten sich vor dem Löthrohr wie reines Steinsalz, indem sie aus dem Schmelzflusse mit der eigenthümlichen krystallinischen Oberfläche erstarren. Im Stauroskop zeigen sie sich einfach-brechend und ohne Polarisation. - Wenn das Gesetz der Symmetrie nicht so wohl begründet wäre, so möchte man durch diese Krystalle verleitet werden, an seiner Realität $\mathrm{zu}$ zweifeln; wie es ist, muss man sie als Ausnahmserscheinungen betrachten, welche fast alle Naturgesetze begleiten, ohne dass wir den Grund daron wissen.

\title{
LI.
}

\section{Ueber die Wirkung der Elektricität und des Lichtes auf die wässrige Lösung gewisser Substanzen.}

\author{
Von
}

Nièpco de Saint-Victor.

(Compt. rend. t. 2, p. 440.$)$

1) Wirkung der Elektricitat. Wenn man in eine Auflösung von salpetersaurem Uranoxyd in der Kälte einige Zeit lang Drehspähne von Kupfer oder Zink bringt, oder besser ein einfaches Element aus einer Kupfer- und einer Zinkplatte bestehend, so geht das gelbe Uransalz in das grüne über und zwar im Verhältniss zu dem Sä̃regrad der Lösung. Da nun die grünen Uransalze, wie Peligot gezeigt hat, die Gold- und Silbersalze reduciren, so bepbachtet man an der erwähnten Lösung, dass sie ebenso 
reducirend wirkt wie eine solche, welche unter gewissen Umständen der Einwirkung des Lichts ausgesetzt worden ist.

Eine Lösung von Weinsäure oder Citronensäure, in welche man während einiger Zeit Kupfer und Zink gebracht hat, reducirt gleichfalls in der Kälte das Chlorgold.

Wenn man die Leitungsdrähte (aus Platin) einer Batterie in rothen Wein, kürzere oder längere Zeit je nach der Stärke des Stroms, taucht, so ändert đer Wein seine Farbe, wird alkoholreicher und nimmt einen brenzlichen Geschmack an, besonders wenn man Funken im Wein erzeugt hat.

Weisser, sehr süsser Wein, durch welchen man einen elektrischen Strom gehen lässt, verliert allen seinen Zucker reducirt die Barreswil'sche Flüssigkeit nicht mehr und wird alkoholreicher.

Eine Zuckerlösung, durch welche zur gleichen Zeit ein Strom ging, zeigte jedoch am Saccharimeter keine Veränderung. Besonders bemerkenswerth ist auch, dass alle erwähnten Lösungen durch Schütteln oder durch längeres Stehen an freier Luft (das grüne Uransalz wird dabei gelb) sehr rasch die Fähigkeit verlieren, Gold- und Silbersalze zu reduciren. Sie behalten aber diese Eigenschaft; wenn sie in einem vollen und luftdicht verschlossenen Gefäss aufbewahrt werden, gerade wie die früher von mir beschriebenen dem Lichte ausgesetzt gewesenen salpetersauren Uranlösungen.

2) Vereinigte Wirkung der Elektricitàt und des Lichts. Wenn man eine schwach angesäuerte Lösung von salpetersaurem Uranoxyd, in welche die Elemente einer einfachen Kette tauchen, dem Lichte aussetzt, so trïbt sich die Flüssigkeit und es entsteht ein violetter Niederschlag, der nach Peligot's Untersuchung mit basisch salpetersaurem Uranoxyd gemengt ist. Diese Flüssigkeit reducirt Goldund Silbersalze sehr energisch. Dor violette Niederschlag, der sich nur bei vereinigter Wirkung der Elektricität und des Lichts bildet, gleicht in Farbe und Eigenschaften der Färbung, welche durch die Wirkung des Lichts auf einem 
Papierblatt entsteht, das diese Farbe in der Dunkelheit nach einer gewissen Zeit verliert.

Dieser violette Niederschlag wird durch Kali grün, nimmt durch Säuren seine ursprüngliche Farbe wieder an und löst sich darin auf.

Taucht man ferner in eine Auflösung von Oxalsäure und salpetersaurem Uranoxyd die Elemente einer einfachen Kette, so entwickelt sie in der Dunkelheit allerdings Elektricität; setzt man aber den Apparat in einem Gefäss von weissem Glas der Sonne aus, so entwickeln sich in der Flüssigkeit Gasblasen (Kohlenoxyd), wodurch sie in förmliches Sieden kommt, besonders beim geringsten Schütteln. In diesem Zustande nimmt die Stärke des elektrischen Stroms sehr zu, wie sich Pouillet durch das Galvanometer überzeugte. Wenn die Oxalsäure in Ueberschuss vorhanden ist, wie es sein muss, damit die Kette lange Zeit wirkt, so bildet sich am Boden des Gefässes oxalsaures Zinkoxyd.

Die Wirkung der Kette ist nicht nothwendig, damit die Lösung aes oxalsauren Uranoxyds unter dem Einflusse des Lichts Kohlenoxyd entwickelt, die Elektricität verstärkt aber die Wirkung des Lichts und umgekehrt.

Elektricität allein veranlasst ebensowenig wie die Wärme (wenn sie nicht über $100^{\circ}$ steigt) in der Lösung des oxalsauren Uranoxyds eine Entwickelung von Kohlenoxydgas.

\section{LII.}

Die Cochenilletinctur und ihre Anwendung in der Alkali- und Acidimetrie.

Von

\section{Lnckow in Köln.}

Die Lakmustinctur ist bisher fast ausschliesslich unter den Farbstoffen benutzt worden, um in der Alkali- und 